University of Nebraska - Lincoln

DigitalCommons@University of Nebraska - Lincoln

1982

\title{
Implications of an Elastic Analysis of In Situ Stress \\ Measurements Near the San Andreas Fault
}

A. McGarr

U.S. Geological Survey

M. D. Zoback

U.S. Geological Survey, zoback@stanford.edu

T. C. Hanks

U.S. Geological Survey

Follow this and additional works at: https://digitalcommons.unl.edu/usgsstaffpub

Part of the Earth Sciences Commons

McGarr, A.; Zoback, M. D.; and Hanks, T. C., "Implications of an Elastic Analysis of In Situ Stress Measurements Near the San Andreas Fault" (1982). USGS Staff -- Published Research. 455.

https://digitalcommons.unl.edu/usgsstaffpub/455

This Article is brought to you for free and open access by the US Geological Survey at DigitalCommons@University of Nebraska - Lincoln. It has been accepted for inclusion in USGS Staff -- Published Research by an authorized administrator of DigitalCommons@University of Nebraska - Lincoln. 


\title{
Implications of an Elastic Analysis of In Situ Stress Measurements Near the San Andreas Fault
}

\author{
A. McGarr, M. D. Zoback, and T. C. Hanks \\ U.S. Geological Survey, Menlo Park, California 94025
}

\begin{abstract}
Twenty-nine measurements of in situ stress obtained with the hydraulic fracturing technique near Palmdale, California, are the basis of an elastic analysis of the state of stress in the Mojave Desert adjacent to the San Andreas fault. The measurements were made at depths extending from 80 to $849 \mathrm{~m}$ and at distances from the fault between 2 and $34 \mathrm{~km}$. The elastic solution indicates a state of deviatoric stress typical for continents in that the inferred depth gradient of the maximum shear stress is about 7.9 $\mathrm{MPa} / \mathrm{km}$. Extrapolation yields an average shear stress in the upper $14 \mathrm{~km}$ of the crust of about $56 \mathrm{MPa}$, a result that is higher than estimates of the average shear stress on the San Andreas fault based on the analysis of heat flow data. This finding is consistent, however, with estimates of fault strength based on laboratory determinations of the coefficient of friction for samples of San Andreas fault gouge if the regional state of deviatoric stress is limited by the strength of the fault zone. If so, then the coefficient of friction of the San Andreas fault zone inferred from the stress field results is about 0.45 . The state of stress does not appear to vary systematically with distance from the San Andreas fault although considerable localized variation is observed. The observations suggest an upper bound of about 0.1 $\mathrm{MPa} / \mathrm{km}$ for the horizontal gradient of the maximum shear stress in the direction perpendicular to the San Andreas fault, a result that implies a corresponding limit of about $1.4 \mathrm{MPa}$ on the shear traction applied to the base of the seismogenic layer. Finally, we demonstrate the potential application of in situ stress data to the direct assessment of accumulated slip, which could be released in a large earthquake. We show that on the basis of a model involving a locked fault, extending to about $22 \mathrm{~km}$, the total fault slip below the locked portion is less than $13 \mathrm{~m}$. A more comprehensive set of stress data could permit the estimation of an even lower bound.
\end{abstract}

\section{INTRODUCTION}

The debate concerning the level of shear stress along major faults, such as the San Andreas in California, has been the subject of many studies in the last 12 years [e.g., Hanks and Raleigh, 1980]. The analysis and modeling of heat flow measurements in the vicinity of the San Andreas fault [e.g., Brune et al., 1969; Lachenbruch and Sass, 1973, 1980] have played a key role on the low-stress side of the argument in that they imply levels of shear stress, as averaged over the top 10-20 km, of the order of $20 \mathrm{MPa}$ or less. The other side of the debate has been well represented by analyses that argue for average shear stresses closer to $100 \mathrm{MPa}$, based on laboratory measurements of frictional strength under realistic conditions of temperature and pressure [e.g., Byerlee, 1978; Brace and Kohlstedt, 1980; Hanks, 1977].

The most direct approach to assessing levels of shear stress in the environs of the San Andreas fault involves measurements and analyses of in situ shear stress. To this end, stress measurements along a horizontal profile in the Mojave desert near Palmdale, California, reported by Zoback and Roller [1979], were analyzed by McGarr [1980], who concluded that although the data indicated somewhat reduced levels of shear stress in the upper $5 \mathrm{~km}$ of the San Andreas fault zone relative to corresponding background values far from the fault, the absolute stress levels, as a function of depth either near to or far from the fault, could not be evaluated because the observations were taken at depths extending only to $230 \mathrm{~m}$.

In the meantime, however, additional measurements have been made to depths of $850 \mathrm{~m}$ in the Mojave desert [Zoback

This paper is not subject to U.S. copyright. Published in 1982 by the American Geophysical Union.

Paper number 2B1016. et al., 1980; Hickman et al., 1982], and, with the enlarged data set, a meaningful analysis of the absolute state of stress near the San Andreas fault is now feasible. This paper presents the results of an elastic analysis of 29 measurements made by using the technique of hydraulic fracturing, which has been extensively discussed by Haimson and Fairhurst [1970] and others, and then discusses some implications of the deduced stress state.

\section{IN Situ STRESSES}

We now review the stress data primarily with a view to deciding how best to analyze them. The stress measurements analyzed here were made at six sites in the Mojave Desert near Palmdale, California (Figure 1). The results from five of these sites have been reported by Zoback et al. [1980] and Hickman et al. [1982]. These five sites form a profile approximately perpendicular to the San Andreas fault near the town of Pearblossom, at distances from the fault between 2 and $34 \mathrm{~km}$. The sixth site near Lake Hughes (Figure 1) is nearly $60 \mathrm{~km}$ to the northwest of the profile. Five of the wells were drilled into quartz monzonite, and the well MOJ1, to the southwest of the San Andreas fault, was in the Punchbowl sandstone formation.

The results of the 29 stress measurements are listed in Table 1 and illustrated in Figures 2 to 4 . Before discussing the magnitudes of the stress components we note that Zoback et al. [1980] determined the orientation of the maximum horizontal principal stress $S_{H \max }$ to be about $\mathbf{N}$ $20^{\circ} \mathrm{W} \pm 15^{\circ}$, which is at an angle close to $45^{\circ}$ from the local strike of the San Andreas fault. This direction for $S_{H \max }$ agrees well with corresponding azimuths of $P$ axes inferred from the focal mechanisms of small earthquakes near Pearblossom (Figure 1) by McNally et al. [1978]. In the coordinate system shown in Figure 1, the component of stress 


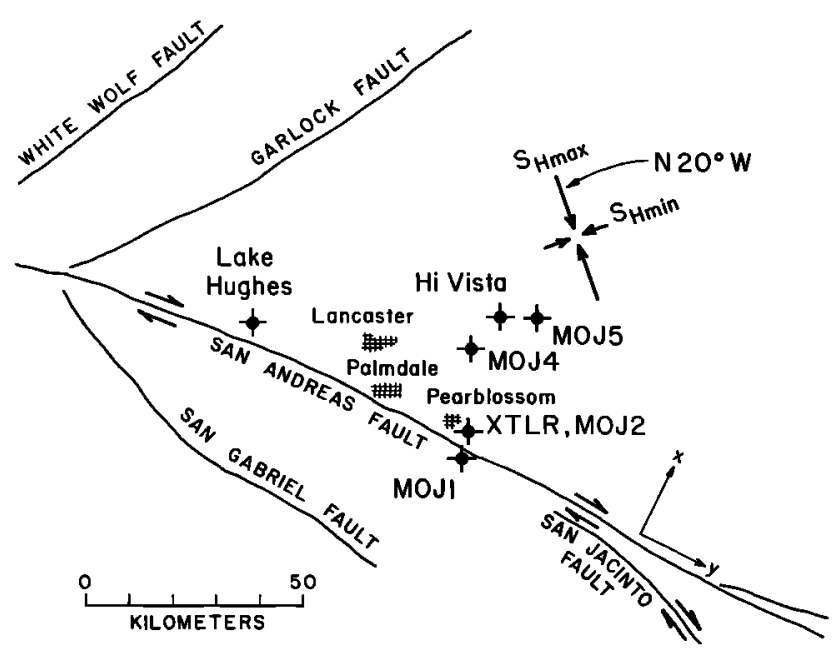

Fig. 1. Map showing locations of wells where stress measurements were made in the Mojave Desert. The local strike of the San Andreas fault here is about $\mathrm{N}^{\circ} 5^{\circ} \mathrm{W}$.

acting on the plane of the San Andreas fault to produce dextral slip is $\tau_{x y}$, which is given by

$$
\tau_{x y}=\frac{S_{H \max }-S_{H \min }}{2}
$$

where $S_{H \text { min }}$ is the minimum horizontal principal stress. The stress component $\tau_{x y}$ is particularly important for the present study partly because of its interaction with the San Andreas fault.

Because the measurements were at depths extending to $850 \mathrm{~m}$ and at distances from the fault of $2-34 \mathrm{~km}$, the data listed in Table 1 are well suited to determining how the state of stress varies as a function of depth $z$ and distance $x$ from the fault. The data, however, are of almost no value in discovering much about variations along strike. As will be seen, the stresses measured at a single depth near Lake Hughes are reasonably compatible with the profile data. Thus, while there is no evidence at present for changes in the state of stress along the strike of the San Andreas fault near Palmdale, the region is not sampled for finding such an effect.

First consider the dependence of the shear stress $\tau_{x y}$ as a function of depth and horizontal position (Figure 2). Generally, there is a fairly clear tendency for $\tau_{x y}$ to increase with depth, although within limited depth intervals in several of the wells $\tau_{x y}$ actually appears to decrease with depth, for example, in the Hi Vista well (Table 1). The depth dependence of $\tau_{x y}$ is best defined by the data from XTLR primarily because these measurements sample a greater depth range than for the other wells.

The horizontal variation of $\tau_{x y}$ is difficult to assess. In the topmost $200 \mathrm{~m}$ or so (Figure 2), this stress component appears to increase with distance from the fault. This increase of $\tau_{x y}$ with $x$ at shallow depths was discussed and analyzed by Zoback and Roller [1979], McGarr [1980], and Hanks [1980]. At greater depths, however, a comparison of the Hi Vista data with observations from XTLR and Lake Hughes suggests, if anything, a slight decrease in $\tau_{x y}$ with $x$, although the data from $\mathrm{Hi}$ Vista show quite an irregular variation with depth. Thus it is difficult at present to argue for a systematic change in $\tau_{x y}$ with distance from the San Andreas fault, a point to which we return later. Rather, one gains the impression from Figure 2 that there may be considerable localized variation in the stress field.

The two horizontal principal stresses (Figures 3 and 4)

TABLE 1. Stresses in the Mojave Desert

\begin{tabular}{|c|c|c|c|c|c|c|c|c|}
\hline Well & $x, \mathrm{~km}$ & $z, \mathrm{~m}$ & $\tau_{x y}, \mathrm{MPa}$ & $\begin{array}{c}S_{H \min }, \\
\mathrm{MPa}\end{array}$ & $\begin{array}{c}S_{H \max }, \\
\mathrm{MPa}\end{array}$ & $S_{v}{ }^{*}, \mathrm{MPa}$ & $\begin{array}{c}\sigma_{1}^{\prime}(\mu=0.85) \\
\mathrm{MPa}\end{array}$ & $\begin{array}{c}\sigma_{1}^{f}(\mu=0.75) \\
\mathrm{MPa}\end{array}$ \\
\hline \multirow[t]{7}{*}{$\overline{\text { XLTR }}$} & 4 & 266 & $2.7 \pm 0.3$ & $7.7 \pm 0.2$ & $13.0 \pm 0.6$ & 7.0 & 23.2 & 20.2 \\
\hline & 4 & 338 & 2.6 & 7.4 & $12.5 \pm 0.5$ & 9.0 & 22.4 & 19.7 \\
\hline & 4 & 561 & 5.7 & 15.0 & $26.4 \pm 0.6$ & 14.9 & 49.5 & 43.1 \\
\hline & 4 & 681 & 5.9 & 14.1 & 25.8 & 18.0 & 41.4 & 36.4 \\
\hline & 4 & 751 & $8.4 \pm 0.5$ & 18.8 & $35.6 \pm 1.0$ & 19.9 & 60.9 & 53.1 \\
\hline & 4 & 787 & $8.2 \pm 0.3$ & $18.3 \pm 0.3$ & $34.6 \pm 0.5$ & 20.9 & 57.3 & 50.1 \\
\hline & 4 & 849 & 8.0 & $19.3 \pm 0.2$ & 35.2 & 22.5 & 59.7 & 52.2 \\
\hline \multirow[t]{5}{*}{ MOJ1 } & 2 & 80 & 0.8 & 2.3 & $3.8 \pm 0.8$ & 2.1 & 6.9 & 6.0 \\
\hline & 2 & 86 & 0.3 & 3.0 & 3.6 & 2.3 & 7.7 & 6.7 \\
\hline & 2 & 134 & 0.8 & 3.2 & 4.7 & 3.6 & 10.1 & 8.9 \\
\hline & 2 & 185 & 0.6 & 5.6 & 7.3 & 4.9 & 16.3 & 14.2 \\
\hline & 2 & 218 & 0.9 & 7.2 & 8.9 & 5.8 & 19.3 & 16.8 \\
\hline \multirow[t]{3}{*}{ MOJ2 } & 4 & 149 & 1.9 & 5.0 & 8.8 & 4.0 & 13.4 & 11.6 \\
\hline & 4 & 167 & 1.9 & 5.1 & 8.9 & 4.4 & 14.6 & 12.7 \\
\hline & 4 & 230 & 2.9 & 8.3 & 14.0 & 6.1 & 20.2 & 17.6 \\
\hline \multirow[t]{3}{*}{ MOJ4 } & 22 & 73 & $2.4 \pm 0.3$ & $4.5 \pm 0.2$ & $9.3 \pm 0.8$ & 1.9 & 6.3 & 5.4 \\
\hline & 22 & 104 & 3.6 & 6.9 & 14.1 & 2.8 & 9.4 & 8.1 \\
\hline & 22 & 179 & 5.4 & 8.1 & 18.8 & 4.7 & 15.5 & 13.5 \\
\hline \multirow[t]{3}{*}{ MOJ5 } & 34 & 140 & 2.9 & 5.7 & 11.4 & 3.7 & 12.3 & 10.7 \\
\hline & 34 & 143 & 3.3 & 7.3 & 13.9 & 3.8 & 12.6 & 11.0 \\
\hline & 34 & 216 & 5.3 & 11.7 & 22.2 & 5.7 & 18.9 & 16.4 \\
\hline Lake Hughes & 4 & 460 & $3.8 \pm 0.5$ & 15.9 & $23.5 \pm 1.0$ & 12.2 & 40.5 & 35.3 \\
\hline \multirow{7}{*}{ Hi Vista } & 32 & 180 & $3.2 \pm 0.3$ & 7.4 & 13.7 & 4.8 & 16.0 & 13.9 \\
\hline & 32 & 227 & 2.5 & 7.1 & 12.1 & 6.0 & 19.9 & 17.3 \\
\hline & 32 & 273 & 1.4 & 5.8 & 8.7 & 7.2 & 17.3 & 15.2 \\
\hline & 32 & 325 & 2.1 & 9.4 & 13.6 & 8.6 & 28.5 & 24.8 \\
\hline & 32 & 493 & 6.3 & 12.4 & 25.0 & 13.1 & 40.2 & 35.1 \\
\hline & 32 & 539 & 2.7 & 11.8 & 17.2 & 14.3 & 35.8 & 31.4 \\
\hline & 32 & 546 & 3.4 & 10.5 & 17.2 & 14.5 & 29.4 & 26.0 \\
\hline
\end{tabular}

${ }^{*}$ Calculated from $S_{v}=\rho g z=26.5(\mathrm{MPa} / \mathrm{km}) z$ [McGarr and Gay, 1978]. 
each have a distribution similar to that of the shear stress $\tau_{x y}$ in that they appear to increase with depth but show an ambiguous dependence on distance from the San Andreas fault; as before, in the top $\mathbf{2 0 0} \mathrm{m}$ each principal stress tends to increase with distance from the fault, whereas at deeper levels the opposite tendency is seen.

Although the vertical principal stress, with an assumed depth gradient of $26.5 \mathrm{MPa} / \mathrm{km}$ (see Figure 3 of $M c$ Garr and Gay [1978]) is the minimum principal stress in the topmost $400 \mathrm{~m}$ or so (Figure 3), it becomes the intermediate principal stress at greater depths. Not surprisingly, $S_{H \max }$ is the greatest principal stress at all depths (Figure 4).

To summarize briefly, the existing stress data (Table 1, Figures 2, 3, and 4) in the Mojave Desert near the San Andreas fault do not seem to argue for any systematic variation in the state of stress with distance away from the San Andreas fault. Furthermore, the good agreement with the other data of the stresses measured at Lake Hughes nearly $60 \mathrm{~km}$ to the northwest of the profile near Pearblossom (Figure 1) is consistent with the assumption that the state of stress does not vary appreciably along strike. Whatever horizontal variation there is in the state of stress appears to be dominated by localized changes sometimes over very short distances; for example, wells MOJ5 and Hi Vista are separated by only about $6 \mathrm{~km}$ (Figure 1) and $\tau_{x y}$ at a depth of $216 \mathrm{~m}$ in the former well is more than twice as large as at $227 \mathrm{~m}$ in the latter (Table 1). The state of stress does, however, change appreciably with depth (Figures 2, 3, and 4). In particular, $\tau_{x y}$, the shear stress that interacts with the San Andreas fault, generally increases with depth. Accordingly, for purposes of the analysis to follow, we conclude that with the present data set it is most realistic to assume that the state of stress varies with depth but not coherently with horizontal position.

\section{ANALYSIS}

Before applying the results of the theory of elasticity to the analysis of the in situ stress data (Table 1), it is necessary to verify that the rocks sampled can be treated as an elastic medium. For present purposes, the rock is taken to be elastic

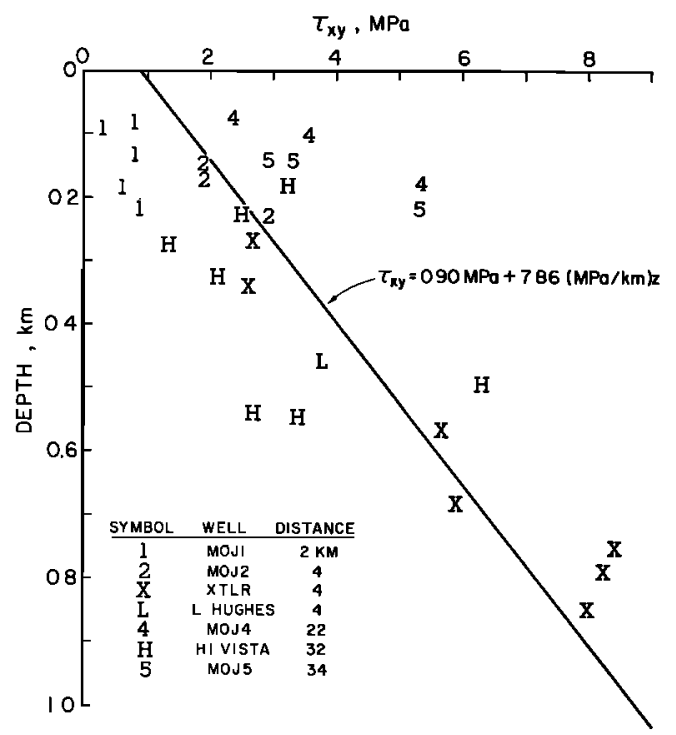

Fig. 2. The horizontal shear stress $\tau_{x y}$ as a function of depth and location.

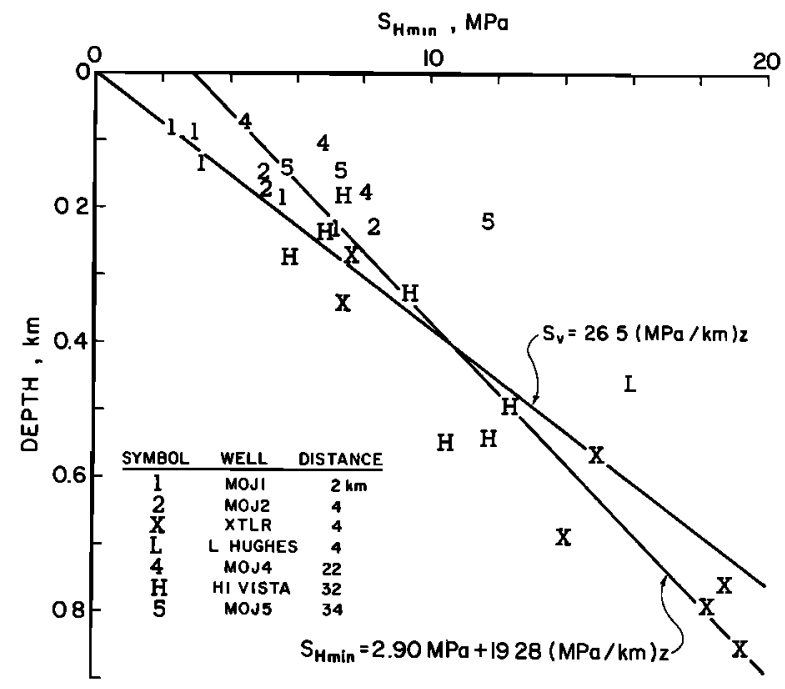

Fig. 3. The minimum horizontal stress $S_{H \min }$ as a function of depth.

if it is not generally close to a state of failure; that is, any deformation should be governed by Hooke's law.

Following Brace and Kohlstedt [1980], we estimate lower limits on the crustal strength by assuming that the crust beneath the Mojave Desert is permeated with cohesionless joints of all orientations and then calculate the failure state of stress on the basis of Byerlee's [1978] law of friction. From these considerations, the maximum principal stress required for failure $\sigma_{\mathrm{I}}{ }^{f}$ is related to the minimum principal stress $\sigma_{3}$ by

$$
\sigma_{1}^{f}-P \simeq A\left(\sigma_{3}-P\right) \quad A=\frac{1+\mu^{2}+\mu\left(\mu^{2}+1\right)^{1 / 2}}{1+\mu^{2}-\mu\left(\mu^{2}+1\right)^{1 / 2}}
$$

where $P$ is the pore pressure and $\mu$ is the coefficient of friction. For $\sigma_{3}-P<110 \mathrm{MPa}$ the coefficient of friction most appropriate for a broad variety of rock types, including granitic rocks and sandstones, has a value of about $\mathbf{0 . 8 5}$ [Byerlee, 1978; Brace and Kohlstedt, 1980]. From the data compiled by Byerlee [1978] it seems unlikely that $\mu$ would have an average value significantly less than 0.75 for the

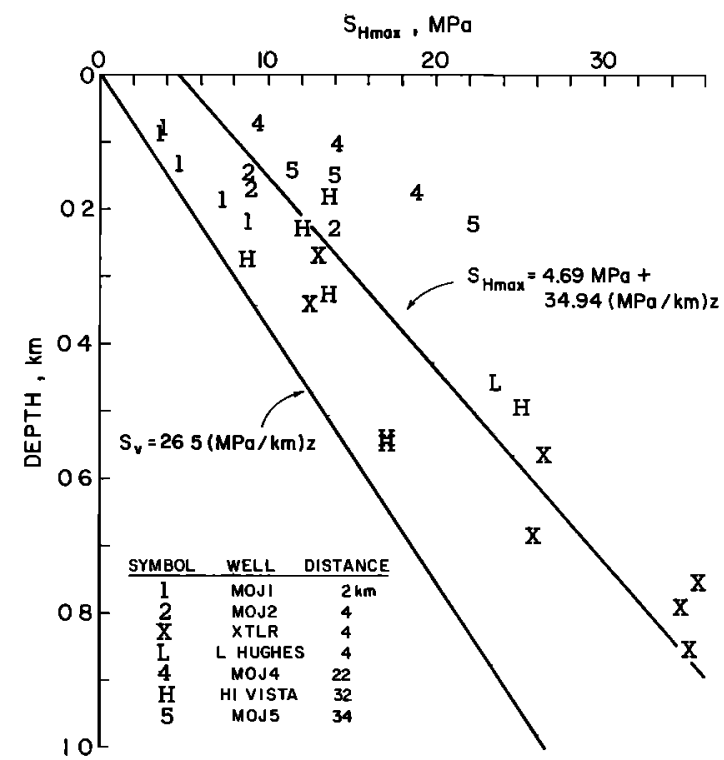

Fig. 4. The maximum horizontal stress $S_{H \max }$ as a function of depth. 


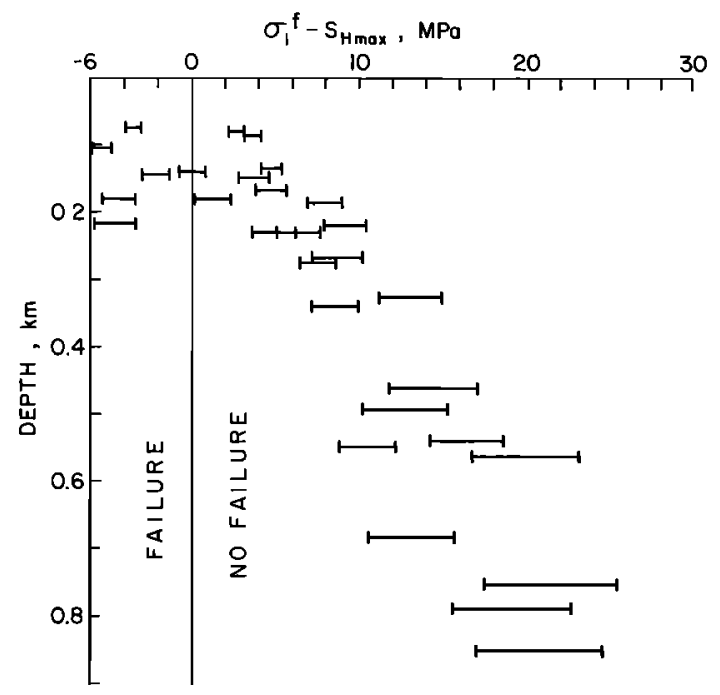

Fig. 5. The difference between the maximum principal stress presumably needed for failure $\sigma_{1}^{f}$ and the measured value of this component $S_{1}$ as a function of depth; $\sigma_{1}^{f}$ (equation (1)) has been calculated for $\mu=0.75$ and $\mu=0.85$, and the horizontal bars indicate the range between these two assumptions.

rocks sampled in the wells beneath the Mojave Desert. Following Zoback et al. [1980] and Hickman et al. [1982] the pore pressure $P$ is taken to be hydrostatic based on the observation that the water table is not much below the top of any of the wells (S. Hickman, oral communication, 1981); thus $P=9.8(\mathrm{MPa} / \mathrm{km}) z$.

Accordingly, $\sigma_{1}^{f}$ was calculated for each of the measurement sites assuming both the most likely value of $\mu$ of 0.85 and $\mu=0.75$ for which $A=4.68$ and 4.00 [Sibson, 1975] in (1), respectively. These results, listed in Table 1 , can be compared to $S_{H \max }$ at each site for the purpose of deciding whether or not the rock is close to a state of failure. From this comparison (Figure 5), it appears that the state of deviatoric stress at nearly all of the sites is substantially below the failure level (Figure 5). The six exceptions are in the upper $220 \mathrm{~m}$ of wells MOJ4 and MOJ5 (Table 1). The observed state of stress progresses away from the failure state with increasing depth. As will be seen, the coefficient of friction of the rock would have to be as low as about 0.45 for the observed stresses to be indicative of a state of failure. Such low coefficients of friction, however, are never observed for rocks such as granite and sandstone [Byerlee, 1978].

At first glance, the points in the failure regime (Figure 5, Table 1) seem paradoxical. Earthquakes do not concentrate near the surface beneath the Mojave. More likely, the failure criterion, equation (1), underestimates the true strength of the upper crust because the assumptions may not be completely appropriate. For example, the existing joints and cracks probably have a nonzero cohesive strength; this departure from the idealized assumptions leading to (1) would be more serious near the surface. Similarly, if the actual pore pressure $\boldsymbol{P}$ is somewhat less than the assumed hydrostat, the true strength would be underestimated, an effect that would be especially marked at shallow depth. In short, the points (Figure 5) that plot in the failure regime are most likely an indication that (1) tends to underestimate the actual strength of the upper crust rather than a paradox.

On the basis that the rock beneath the Mojave Desert does not seem to be generally close to a state of failure, we assume that it is an elastic medium for purposes of analysis. The region included in our analysis is the elastic-brittle layer of the Mojave Desert near the San Andreas fault (Figure 1) but excluding the actual fault zone. Following Lachenbruch and Sass [1980], this layer is taken to extend to a depth of 14 $\mathrm{km}$, below which temperature-dependent deformation becomes important, thus violating the assumption of long-term strength necessary for an elastic analysis [e.g., Brace and Kohlstedt, 1980; Sibson, 1982].

If the state of stress does not vary horizontally and if the directions of the horizontal principal stresses do not change with depth, as appears to be indicated by the observations [Zoback et al., 1980], then from results developed by $M c G a r r$ [1980], each of $\tau_{x y}, S_{H \min }$, and $S_{H \max }$ must be a linear function of depth $\boldsymbol{A}+\boldsymbol{B z}$. Furthermore, these depth functions can be used to extrapolate the state of stress below the domain of the observations, in the top $850 \mathrm{~m}$, to the bottom of the elastic-brittle layer. We note, however, that the analysis leading to the result that the stress components vary linearly with depth assumes isotropic elastic moduli and strain compatibility as well as Hooke's law [McGarr, 1980]. These conditions are unlikely to be satisfied everywhere in the domain of interest, and so our analysis proceeds on the assumption that departures from these idealizations are not sufficiently coherent on a broad enough scale to vitiate the results.

To determine the coefficients of the linear depth functions for the horizontal stress components we have fit regression lines to the observations (Figure 2, 3, and 4). A fit of $A_{1}+$ $B_{1} z$ to $\tau_{x y}$ yielded (Figure 2)

$$
\tau_{x y}=(0.90 \pm 0.47) \mathrm{MPa}+(7.86 \pm 1.18)(\mathrm{MPa} / \mathrm{km}) z
$$

The depth gradient determined here for $\tau_{r y}$ has a magnitude similar to that found for a much larger data set of maximum shear stresses measured in southern Africa, Australia, and North America, of $6.6 \pm 1.0 \mathrm{MPa} / \mathrm{km}$, although the intercepts of the fits to the two sets of data differ significantly [McGarr, 1980]. Thus the inferred gradient for $\tau_{x y}$ in the Mojave Desert appears to be typical for continental crusts.

A regression fit of $A_{2}+B_{2} z$ to $S_{H \min }$ resulted in (Figure 3)

$S_{H \min }=(2.90 \pm 0.60) \mathrm{MPa}+(19.28 \pm 1.52)(\mathrm{MPa} / \mathrm{km}) z$

The standard deviation of $B_{2}$ is only $8 \%$ of that coefficient and so the depth gradient of $S_{H \min }$ is exceptionally well determined.

A regression fit of $A_{3}+B_{3} z$ to $S_{H \max }$ yielded (Figure 4)

$S_{H \max }=(4.69 \pm 1.40) \mathrm{MPa}+(34.94 \pm 3.54)(\mathrm{MPa} / \mathrm{km}) z$

Although the standard deviations of the depth gradients given by (2), (3), and (4) are each acceptably small, there is nevertheless an unsatisfactory aspect to the determinations of $B_{1}, B_{2}$, and $B_{3}$. Namely, these gradients depend heavily on data from the XTLR well, partly because this well extends to the greatest depth, but also owing to the regularity of the increase with depth of the horizontal stress components at this site (e.g., Table 1). Measurements in the second deepest well, Hi Vista, although broadly consistent with the XTLR results, show an erratic depth dependence (e.g., Figures 2 and 4). Thus the Hi Vista data alone are of little use in establishing credible depth gradients, and so some of the 


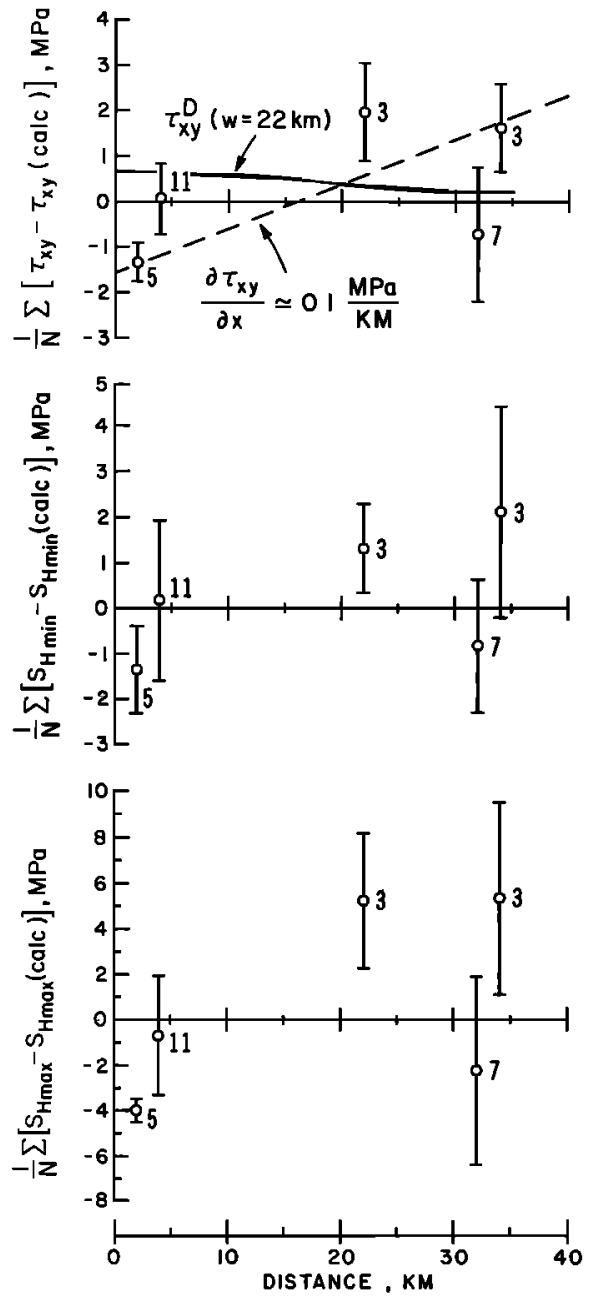

Fig. 6. Average residuals of the stress components as a function of distance from the fault. The calculated stresses are from equations (2), (3), or (4), and the observations are listed in Table 1. The numbers by each point indicate how many measurements were considered in determining a particular residual. In the topmost graph, the stress $\tau_{x y}{ }^{D}$ due to fault slip of $3.1 \mathrm{~m}$ at depths below $22 \mathrm{~km}$ is shown as a solid line (equation (11)). The dashed line simply provides an approximate indication of the maximum horizontal gradient in $\tau_{x y}$ that might escape detection due to the localized variation in the observations.

most important conclusions of this study, to be discussed, rely very much on data from a single well.

Before discussing some implications of the state of stress determined here, we examine further the assumption that the state of stress is not a coherent function of distance from the San Andreas fault. To reassess the degree of $x$ dependence of the stress state, average residuals and their standard deviations at each of the five distances from the fault were determined by using equations (2), (3) and (4) to calculate predicted stresses as a function of depth (Figure 6). With the exceptions of the points at $x=2 \mathrm{~km}$ (MOJ1) for $\tau_{x y}$ and $S_{H \max }$, all of the residuals are within two standard deviations of the overall mean. Thus the analysis represented in Figure 6 is generally consistent with our assumption that the state of stress does not vary systematically with distance from the San Andreas fault.

The most substantial departure of the state of stress from the regional mean (Figure 6) is at $x=2 \mathrm{~km}$ in the Punchbowl sandstone formation, where all three components have rath- er low values. There are several possible factors that might be responsible for the reduced level of stress down this well. First, these were the only measurements not made in granitic rock. Second, this was the only well to the southwest of the San Andreas fault and is located near the foot of the steeply rising San Gabriel mountains, where the local topography might be expected to reduce the horizontal stress components [e.g., Jaeger and Cook, 1976; McTigue and Mei, 1981]. Because of these and other possibilities, it seems premature at this time to attribute the low stresses measured in the Punchbowl formation solely to the proximity of this site to the San Andreas fault (Figure 1).

As an additional check on the possibility of a systematic $x$ dependence in the state of stress, the observations were divided into two sets, one including measurements made within $5 \mathrm{~km}$ of the fault and the other comprising data taken at $x>20 \mathrm{~km}$. Separate regression lines having the same forms as (2), (3), and (4) were fit to the two data sets and $F$ tests [e.g., Breiman, 1973] were applied to determine whether or not the data warranted a model with two different regional stress states. The results of these tests indicated that two distinct stress states are not required at the $99 \%$ confidence level.

In short, it still seems most realistic, after this reexamination, to analyze the stress data assuming no systematic horizontal variation. At the same time, it should be borne in mind that there is considerable variability in the state of stress beyond that implied by equations (2), (3), and (4), which cannot be explained on the basis of the measurement errors indicated in Table 1 (Figures 2, 3, and 4).

\section{Discussion}

We now explore some of the tectonic implications of equations (2), (3), and (4), which, we think, are currently the most realistic representation of the regional state of stress in the elastic-brittle layer of the crust beneath the Mojave Desert near Palmdale. All of the following discussion relies on our extrapolation of the state of stress downward to a depth of $14 \mathrm{~km}$ based on measurements made only in the top $6 \%$ of this layer. Although such a substantial extrapolation is arguably inadvisable, we have nevertheless decided to proceed on the optimistic assumption that equations (2), (3), and (4) constitute a correct description of the broad-scale stress state near Palmdale. Part of our justification for proceeding is that the data set (Table 1) that serves as a basis for this elastic analysis is by far the most comprehensive ever obtained in such a limited region (Figure 1). Thus even though these stress observations may not be well suited in some respects to inferring the state of stress throughout the elastic-brittle layer, they are the best available, and so we feel an obligation to derive as much inference from these data as possible. At the very least, the following results and implications provide some guidance for planning future observations.

Average shear stress. From equation (2), the average level of shear stress in the top $14 \mathrm{~km}$ of the crust is inferred to be

$$
\overline{\tau_{x y}}=56 \pm 8 \mathrm{MPa}
$$

This result is interesting because $56 \mathrm{MPa}$ is greater by a factor of between 2 and 3 than the upper bound of about 20 MPa for the average shear stress inferred by Lachenbruch and Sass [1980] on the basis of modeling heat flow data. 56 
$\mathrm{MPa}$ is also about a factor of 2 less than the average shear stress based on laboratory estimates of the frictional strength of rocks [e.g., Byerlee, 1978]. The discrepancy between (5) and the results of modeling heat flow is more serious than the discrepancy with regard to the laboratory measurements of frictional strength, which, as will be seen, can be explained.

Because of the impressive rigor of the argument based on modeling heat flow data leading to an upper bound on $\overline{\tau_{x y}}$ in the upper $14 \mathrm{~km}$ of about $20 \mathrm{MPa}$ [Lachenbruch and Sass, 1980], it would clearly be preferable to test this conclusion by direct observation of the stress field rather than by means of extrapolation (equation (2)). How deep would stress measurements have to be made to distinguish between the heat flow results and (2)? According to (2) the shear stress $\tau_{x y}$ is likely to reach a level of $20 \mathrm{MPa}$ between 2 and $3 \mathrm{~km}$ depth, and so it appears that in situ stress observations down a well $3.5-4 \mathrm{~km}$ deep could provide the necessary information.

Tectonic stress state. It is of interest to compare the state of stress given by equations (3) and (4) and that implied by the tectonic setting of the Mojave Desert. Throughout most of the seismogenic layer of the crust the average gradient of the two horizontal principal stresses is

$$
\frac{B_{2}+B_{3}}{2}=27.1 \mathrm{MPa} / \mathrm{km}
$$

whereas the vertically oriented principal stress has an assumed gradient of $26.5 \mathrm{MPa} / \mathrm{km}$. Thus the intermediate principal stress, oriented vertically, is almost exactly the average of $S_{H \min }$ and $S_{H \max }$ implying a state of stress in excellent accord with the wrench tectonics of the Mojave block. More specifically, the ratio $\left(S v-S_{H \min }\right) /\left(S_{H \max }-\right.$ $\left.S_{H \min }\right)$ has a value of 0.46 from (3) and (4), if the $A$ 's are neglected, whereas, according to Hill [1982], wrench tectonics are indicated if this ratio falls in the range between 0.25 and 0.75 .

San Andreas fault zone strength. We now address the question of what might limit the state of deviatoric stress in the Palmdale region, having concluded before that the granitic rocks and sandstones of this area are generally not near a state of failure (Figure 5). The most obvious tectonic feature that might limit the crustal shear stress is the San Andreas fault zone, presumably because its frictional resistance to shear displacement is substantially reduced by the presence of clays. For example, Morrow et al. [1982] found that the coefficient of friction for various saturated fault gouges and clays ranged from 0.21 to 0.58 . If the San Andreas fault zone is, in fact, limiting the regional deviatoric stress, then the state of stress represented by equations (2), (3), and (4) can be analyzed to infer the coefficient of friction $\mu$ of the fault zone.

We assume that the San Andreas fault zone is in a state of failure according to the Coulomb [1773] failure criterion, modified to include the effects of pore pressure

$$
\tau_{x y}=\tau_{0}+\left(S_{n}-P\right) \mu
$$

where $\tau_{0}$ is the cohesive shear strength and $S_{n}$ is the component of stress normal to the fault plane. The pore pressure $P$ is taken as hydrostatic as before, and so its depth gradient is $9.8 \mathrm{MPa} / \mathrm{km}$. Because the principal horizontal stresses are oriented at about $45^{\circ}$ to the local fault strike (Figure 1) the normal stress $S_{n}$ is given by

$$
S_{n}=\frac{S_{H \max }+S_{H \min }}{2}
$$

Given that $\tau_{0}$ of equation (6) and $A_{2}$ and $A_{3}$ of equations (3) and (4) are of negligible importance throughout the crustal section, excluding the topmost $500 \mathrm{~m}$ or so, the gross coefficient of friction for the San Andreas fault zone is given by

$$
\mu \simeq \frac{\tau_{x y}}{S_{n}-P} \simeq \frac{B_{1}}{1 / 2\left(B_{2}+B_{3}\right)-P} \simeq 0.45
$$

Aside from the uncertainties associated with $B_{1}, B_{2}$, and $B_{3}$, the pore pressure $\boldsymbol{P}$ is a major source of uncertainty in (7) because, unlike the crust outside the fault zone, there is no direct evidence regarding $P$. Because fault gouges tend to have low permeabilities due to clay content, the possibilities of either a superhydrostatic $\boldsymbol{P}$ or subhydrostatic $\boldsymbol{P}$ certainly exist. Currently, however, it seems most realistic to assume that $P$ is the hydrostat, similar to what is observed directly in the wells outside the fault zone in this area. With these qualifications in mind, we note that the coefficient of friction given by (7) is well within the range of laboratory values measured by Morrow et al. [1982].

This discussion of how the level of deviatoric stress might be limited raises the obvious question of the cause of a regional shear stress. An alternative version of this question is, What would the state of stress be in the absence of the San Andreas fault, or other active throughgoing crustal faults in the Mojave Desert? Although we are not in a position to answer these questions definitively, we take this opportunity to review a model of remote loading that is consistent with the observations. Consider the San Andreas fault stress province as delineated, for example, by Zoback and Zoback [1980]. To the extent that the state of stress is uniform horizontally throughout this stress domain, which extends for substantial distances on either side of the San Andreas fault itself, the loading that gives rise to the regional state of deviatoric stress must occur at the boundaries of the domain. As discussed in detail by McGarr [1982], the type of loading advocated here involves shear tractions applied to the base of the elastic-brittle layer in a direction normal to the transition zone separating the San Andreas fault province from adjacent stress domains. This mechanism yields deviatoric stresses that increase linearly with depth [McGarr, 1982] in accord with observations compiled, for example, by $M c$ Garr [1980]. If this type of loading mechanism is operative, then the state of deviatoric stress in the absence of the San Andreas fault would be higher than we think it is now because the crust would have a greater strength to resist the boundary loading forces. The deviatoric stress would still increase linearly with depth, however, although the shear stress $\tau_{x y}$ would have greater magnitude. Although the San Andreas fault is perhaps the most obvious factor limiting the level of $\tau_{x y}$, the result that $\tau_{x y}$, as well as the other deviatoric stress components, increases linearly with depth is much more likely a consequence of the remote loading by means of basal shear tractions than the frictional strength of the fault zone.

Horizontal stress gradients and basal shear tractions. Even though the overall data set may not indicate a variation in the state of stress with distance from the fault, it is entirely possible that such a variation may exist but be overwhelmed 


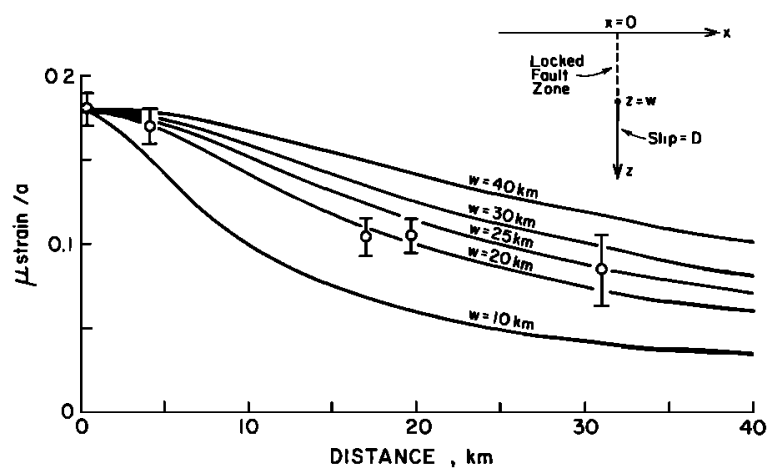

Fig. 7. Rates of strain change $\dot{\varepsilon}_{x y}$ averged over five geodetic networks and theoretical rates of strain change calculated on the basis of the fault zone model schematically illustrated in the upper right hand side of the figure.

by the 'noise' of the localized effects. It is straightforward, however, the estimate upper limits to the $x$ dependence of the state of stress. For the component $t_{x y}$ this limit (Figure 6, top) appears to be

$$
\frac{\partial \tau_{x y}}{\partial x}<0.1 \mathrm{MPa} / \mathrm{km}
$$

The greatest source of uncertainty in (8) involves the possibility that the state of stress below a depth of $500 \mathrm{~m}$ or so may show much more variation with $x$ than indicated by the measurements (Figure 6, top). Equation (8) assumes that shallow and deep level stresses show a similar $x$ dependence. One situation that would render (8) incorrect is that $B_{1}$ (equation (2)) varies significantly with $x$. In essence, the validity of (8) requires that any $x$ dependence is due to a term added to (2) rather than multiplying the depth gradient $B_{1}$ because the latter type of $x$ dependence could easily escape detection. Had the measurements down the Hi Vista well been adequate for the purpose of independently confirming the value obtained for $B_{1}$ then (8) could be accepted with much more confidence than at present.

Equation (8), if true for the elastic-brittle layer, implies a corresponding limit on the basal shear traction $\tau_{y z}(z=14$ $\mathrm{km})$. Consider a block that is long in the $y$ direction parallel to the strike of the San Andreas fault, $1 \mathrm{~km}$ wide in the $x$ direction, and $14 \mathrm{~km}$ deep. Static equilibrium requires that the force on this block in the $y$ direction due to the gradient of $\tau_{x y}$ in the $x$ direction be balanced by an opposite force due to the component of shear stress $\tau_{y z}$ acting on the base of the block. Thus for the basal shear traction, from (8),

$$
\tau_{y z}(z=14 \mathrm{~km}) \leq 1.4 \mathrm{MPa}
$$

This rather low bound on the basal shear stress may be an important constraint for models that involve a partial decoupling of the seismogenic layer from the lower crust [e.g., Lachenbruch and Sass, 1973, 1980; Prescott and Nur, 1981].

Fault loading and stress distribution. To relate the in situ stress observations to the strain accumulation across the fault zone or, equivalently, the potential slip of a future earthquake, it is necessary to consider a specific model of fault slip at depth. Because of (9), it seems inadvisable at present to analyze models involving a partially decoupled seismogenic layer on top of a ductile layer of broadly distributed slip [e.g., Prescott and Nur, 1981]. Rather, we consider the more usual model for which slip occurs continu- ously across the San Andreas fault at a rate $\dot{D}$ below a locked section, which extends from the surface to depth $w$, and across which no slip occurs between major earthquakes [e.g., Savage, 1975]. In the appendix we argue that the trilateration data from networks in the general region of Figure 1 are most consistent with

$$
\begin{aligned}
w & =22 \mathrm{~km} \\
\dot{D} & =2.5 \mathrm{~cm} / \mathrm{a}
\end{aligned}
$$

A long-term fault slip rate of $2.5 \mathrm{~cm} / \mathrm{a}$ agrees well with the results of studies of the Holocene geology both at Pallett Creek near Pearblossom [Sieh, 1978] and near Cajon Pass to the southeast [Weldon and Sieh, 1981].

At first glance, our conclusion that the locked zone extends to $22 \mathrm{~km}$ seems at odds with the model employed here of an elastic-brittle or seismogenic layer of thickness 14 $\mathrm{km}$. This apparent discrepancy, however, is simply an artifact of modeling the slip below the locked zone as a single dislocation line (uniform slip). This single dislocation would, in fact, be situated at the 'center of mass' of the actual distribution of dislocations [e.g., Cottrell, 1953]. Thus $22 \mathrm{~km}$ represents the mean depth of the dislocation distribution which lies some undefined distance below the actual upper edge of the slipping portion of the fault (Figure 7).

Before relating these results from the geodetic data to the stress information, it is necessary to emphasize the nonuniqueness and the oversimplified nature of the model. Other models involving some sort of distributed slip at depth could also yield good fits to the strain data. Furthermore, the model is too simple in that the San Andreas fault is assumed to be perfectly straight and the possible effects of other faults, notably the Garlock, are neglected. Judging from the geological evidence, however [e.g., Crowell, 1973], this latter deficiency may not be serious.

A major difference between the stress and strain rate measurements is that the stress measurements indicate the absolute level to which the rock is loaded, whereas the geodetic data are sensitive to rates of ongoing geologic processes. To relate the strain accumulation model of Figure 7 to the in situ stresses we must assume that slip at depth has built up over a given period of time. Perhaps the most straightforward assumption is that slip has accumulated at a rate of $2.5 \mathrm{~cm} / \mathrm{yr}$ since the time of the great 1857 earthquake $\left(M \simeq 8 \frac{1}{4}\right)$ or for about 124 years. Thus we compute the shear stress $\tau_{x y}$ for a total fault slip of $3.1 \mathrm{~m}$ at depths below $22 \mathrm{~km}$. The contribution to $\tau_{x y}$ due to fault slip is [e.g., Cottrell, 1953]

$$
\tau_{x y}{ }^{D}=\frac{G D(w-z)}{2 \pi\left[(w-z)^{2}+x^{2}\right]}
$$

where $G$ is the modulus of rigidity.

To evaluate $\tau_{x y}{ }^{D}$ for comparison with the stress data in the uppermost crust, we set $z=0, D=3.1 \mathrm{~m}, w=22 \mathrm{~km}$, and $G$ $=30,000 \mathrm{MPa}$ and allow $x$, the distance from the fault, to vary. The result of this calculation is shown in the top portion of Figure 6, where we see that the possible contribution to $\tau_{x y}$ from deep slip on the fault varies from $0.67 \mathrm{MPa}$ at the fault to $0.19 \mathrm{MPa}$ at a distance of $35 \mathrm{~km}$. It is clear that with the existing 'noise,' or unexplained local variation in the stress data, there is no possibility of detecting such a slipinduced stress change. 
Note, however, that the average shear stress residuals for wells at $x=4$ and $32 \mathrm{~km}$, which cover a much greater depth range than at the other three distances, indicate a reduction in $\tau_{x y}$ with increasing $x$ similar to that implied by (11) (Figure 6). Although this observed reduction is not statistically significant, this apparent agreement regarding the reduction in $\tau_{x y}$ between measurements in the deeper holes and (11) suggests that making measurements in relatively deep wells might be one means of reducing the 'noise' in the stress data to the level at which the contribution due to $\tau_{x y}{ }^{D}$ (equation (11)) would be detectable. Another advantage to making deep measurements for purposes of determining $\tau_{x y}{ }^{D}$ is that the magnitude of this stress contribution increases with depth $z$ (equation (11)).

Although the present data set is inadequate for purposes of detecting our estimate of $\tau_{x y}{ }^{D}$, in situ measurements are capable, at least in principle, of yielding direct information about the loading on locked sections of the fault and, in particular, the corresponding accumulated slip. Even with the available stress information, it is possible to at least estimate upper limits on the amount of accumulated slip at depth, assuming that the model utilized here (Figure 7) is appropriate. One method of estimating such a limit is to consider the total change in shear stress with distance from the fault implied by (11). If we set $z=0$, then the total change from $x=0$ to $x \gg w$ is theoretically $\Delta \tau_{x y}{ }^{D}=G D /$ $2 \pi w$. In view of the shear stress residuals (Figure 6), it seems likely that if $\Delta \tau_{x y}{ }^{D}$ were as large as $3 \mathrm{MPa}$ there would have been a noticeable effect. Thus if $\tau_{x y}{ }^{D}<3 \mathrm{MPa}$, then for $w=$ $22 \mathrm{~km}, D<13 \mathrm{~m}$. Although this rather large bound on accumulated slip is not at all reassuring from the viewpoint of seismic risk, this calculation serves, nevertheless, to illustrate how improved stress information in the future might provide useful indications of the potential for seismic displacement.

\section{Conclusions}

To the extent that the state of stress in the general vicinity of Palmdale does not vary systematically in the horizontal directions, and given that the rock beneath the Mojave Desert does not appear to be generally close to failure, then from the theory of elasticity the stress components must be linear functions of depth that are readily determined from the data (equations (2), (3) and (4)). If the preceding conditions hold, then these functions describe the stress field throughout the elastic-brittle layer, assumed here to have a thickness of $14 \mathrm{~km}$. The depth gradient of the shear stress, $7.86 \pm 1.18$ $\mathrm{MPa} / \mathrm{km}$, is typical of what has been found for continental crustal sections. Furthermore, the inferred state of stress is in good accord with the regional wrench tectonics in that the intermediate vertical principal stress is almost exactly the average of the two horizontal principal stresses throughout most of the crustal section. If the regional deviatoric stress is limited by the strength of the San Andreas fault zone, then its inferred gross coefficient of friction is 0.45 , a finding that is consistent with laboratory results.

The average level of shear stress of $56 \mathrm{MPa}$ (equation (5)) in the top $14 \mathrm{~km}$, inferred from the observations, is a factor of nearly 3 greater than the corresponding upper bound that results from modeling heat flow measurements, Even if $\overline{\tau_{x y}}$ is reduced by 2 standard deviations to $40 \mathrm{MPa}$, a discrepancy of a factor of 2 remains.
The stress observations currently suggest an upper bound on the gradient of shear stress $\tau_{x y}$ in the $x$ direction (Figure 1) of about $0.1 \mathrm{MPa} / \mathrm{km}$. This bound on the horizontal gradient implies rather low limits on the shear traction at the base of the elastic-brittle layer of $1.4 \mathrm{MPa}$.

Finally, our demonstration of how the in situ stress observations can be analyzed to place bounds on the potential for slip during a major earthquake may prove to be of considerable importance if means are found to estimate the $x$ dependence (Figure 1) of the state of stress somewhat more precisely. The upper bound on accumulated slip of about 13 $\mathrm{m}$ is about a factor of 3 greater than the slip estimated by Sieh [1978] to have occurred during the great 1857 earthquake near Pearblossom. Thus, a factor of 3 or 4 improvement in our ability to resolve horizontal stress gradients might provide the means of directly estimating accumulated fault slip at depth.

\section{Appendix: Modeling Horizontal Strain ACCUMULATION}

In brief review, the accumulation of shear strain near Palmdale is broadly distributed over the San Andreas fault. Analysis of triangulation data measured in 1932 and 1952 (before the Kern County earthquake of 1952) indicates that at distances $40 \mathrm{~km}$ from the fault the rate of dextral tensor shear-strain accumulation is roughly half of its value of about $0.3 \mu$ strain/a next to the fault [Thatcher, 1979; W. Thatcher, private communication, 1981].

Because estimates of strain accumulation from triangulation data have large uncertainties, we have attempted to refine the determination of the pattern of strain accumulation on the basis of more recent trilateration results reported by Savage et al. [1981] and King et al. [1982]. Table 2 lists average rates of tensor shear strain accumulation $\dot{\varepsilon}_{x y}$ as determined within four subdivisions of the Tehachapi network by King et al. [1982] largely to the northeast of the fault and within the Los Padres network, mostly to the southwest. Also, listed are the average distances of each of the five networks from the San Andreas fault as well as the 'standard deviations' $\sigma$ of the benchmark distances.

The average rate of strain accumulation within each network is shown as a function of distance from the San Andreas fault in Figure 7. We see that the trilateration data are at least qualitatively consistent with the triangulation results in that a broad region of strain accumulation is indicated.

To analyze the observed pattern of strain accumulation in conjunction with the deduced shear stress, we fit a simple model of uniform fault slip below a locked region of no slip extending from the surface to a depth $w$. The rate of dextral shear strain accumulation for such a model is [Savage and Burford, 1973]

$$
\dot{\varepsilon}_{x y}=\frac{\dot{D}}{2 \pi} \frac{w}{w^{2}+x^{2}}
$$

where $\dot{D}$ is the annual rate of fault slip below depth $w$. By using the strain data of Table 2 , we shall evaluate $\dot{D}$ and $w$.

Because equation (A1) is appropriate for point measurements of strain rate, whereas the observations are averages over networks, it is necessary to convert (A1) into an expression for strain rate as averaged over a distance 
TABLE 2. Strain Accumulation Near San Andreas Fault

\begin{tabular}{|c|c|c|c|}
\hline Network & $\dot{\varepsilon}_{x y}, \mu$ strain/a & $\begin{array}{c}\text { Distance, }{ }^{*} \\
\text { km }\end{array}$ & $\underset{\mathrm{km}}{\sigma \text { (Distance) }}$ \\
\hline $\begin{array}{l}\text { Palmdale } \\
\text { S.A. Region } \\
\text { Tehachapi } \\
\text { Los Padres } \\
\text { Sub Garlock } \dagger\end{array}$ & $\begin{array}{l}0.180 \pm 0.01 \\
0.170 \pm 0.01 \\
0.105 \pm 0.01 \\
0.105 \pm 0.01 \\
0.085 \pm 0.02\end{array}$ & $\begin{array}{r}-0.3 \\
4.1 \\
17.0 \\
-19.7 \\
31.0\end{array}$ & $\begin{array}{r}3.6 \\
10.4 \\
20.2 \\
19.7 \\
21.1\end{array}$ \\
\hline
\end{tabular}

*Distances to the northeast of the fault are positive.

$\dagger$ Named Garlock by King et al. [1982], but not the same as the Garlock network discussed, for example by Savage et al. [1981].

interval. Integration of equation (A1) yields for the average strain rate

$$
\overline{\dot{\varepsilon}_{x y}}=\frac{\dot{D}}{2 \pi\left(x_{2}-x_{1}\right)}\left[\tan ^{-1} \frac{x_{2}}{w}-\tan ^{-1} \frac{x_{1}}{w}\right]
$$

where $x_{1}$ and $x_{2}$ define the distance interval over which the average is taken.

To a first approximation, four of the networks listed in Table 2 extend in one direction from the San Andreas fault. The Palmdale network is quite small and straddles the fault and so is most realistically treated as a point strain measurement (equation (A1)). The San Andreas Region, Tehachapi, and Sub Garlock networks extend northeastward, whereas the Los Padres network is largely to the southwest of the fault.

To calculate the theoretical curves in Figure 7 for various values of $w, \dot{D}$ was first determined by using the strain rate over the Palmdale network in equation (A1) with $x=0$; thus all curves agree perfectly with the Palmdale result. Then the average strain rate at each distance from the fault was calculated by setting $x_{1}=0$ and $x_{2}$ equal to twice the particular centroid distance in equation (A2); for example, to calculate $\dot{\varepsilon}_{x y}$ at a distance of $10 \mathrm{~km}, x_{2}=20 \mathrm{~km}$ in (A2). We see in Figure 7 that the locked region appears to extend to depths of 20-25 km.

The results of a somewhat more exact means of analyzing the strain rates listed in Table 2, in terms of the model of fault slip below a locked zone, are summarized in Table 3 . For each network the theoretical average strain rates have been calculated by setting $x_{1}$ and $x_{2}$ to the centroid distance minus or plus a 'standard deviation,' respectively. As before, $\dot{D}$ for each value of $w$ is adjusted to yield perfect agreement for the Palmdale network. We see (Table 3) that the root mean square residual is minimized for $w=22$ to $23 \mathrm{~km}$; a residual $r_{i}$ is the difference between observation and theory over network $i$. Thus the approximate result illustrated in Figure 7

TABLE 3. Determination of $\dot{D}$ and $w$

\begin{tabular}{ccc}
\hline$w, \mathrm{~km}$ & $\dot{D}, \mathrm{~cm} / \mathrm{a}$ & $\begin{array}{c}\left(\Sigma r_{1}^{2}\right)^{1 / 2} \\
\mu \text { strain/a* }\end{array}$ \\
\hline 10 & 1.18 & 0.084 \\
15 & 1.73 & 0.048 \\
20 & 2.29 & 0.023 \\
22 & 2.51 & 0.019 \\
23 & 2.62 & 0.019 \\
25 & 2.84 & 0.022 \\
30 & 3.41 & 0.038 \\
40 & 4.55 & 0.065 \\
\hline
\end{tabular}

${ }^{*} r_{\text {, }}$ is the difference between observation and theory over network $i$. is in good agreement with the more exact determination of $w$ summarized in Table 3.

We conclude from Table 3 and Figure 7 that the model in best agreement with the strain data in the general vicinity of Palmdale has

$$
\begin{aligned}
w & =22 \mathrm{~km} \\
\dot{D} & =2.5 \mathrm{~cm} / \mathrm{a}
\end{aligned}
$$

Note added in proof. A more exact and comprehensive analysis of the problem discussed in the appendix is presented by King et al. [1982].

Acknowledgments. Steve Hickman kindly provided the in situ stress data measured in the Hi Vista well before publication and engaged in many useful discussions with us. Nancy King gave us information on rates of strain accumulation within various geodetic networks, also in advance of publication. James Savage suggested the use of equation (A2) for the interpretation of the strain data. Discussions with A. Lachenbruch, W. Prescott, D. Pollard, J. Langbein, J. Healy, G. Fuis, and W. Ellsworth helped to clarify some of the issues discussed here. The manuscript benefited from reviews by A. H. Lachenbruch, M. McNutt, and J. C. Savage; R. Sibson helpfully commented on an earlier version of this report.

\section{REFERENCES}

Brace, W. F., and D. L. Kohlstedt, Limits on lithospheric stress imposed by laboratory experiments, J. Geophys. Res., 85, 6248$6252,1980$.

Breiman, L., Statistics With a View Toward Applications, Houghton Mifflin, Boston, Mass., 1973.

Brune, J. N., T. L. Henyey, and R. F. Roy, Heat flow, stress, and rate of slip atong the San Andreas fault, California, J. Geophys. Res., 74, 3821-3827, 1969.

Byerlee, J. D., Friction of rocks, Pure Appl. Geophys., 116, 615626, 1978.

Cottrell, A. H., Dislocations and Plastic Flow in Crystals, Clarendon, Oxford, 1953.

Coulomb, C. A., Sur une application des regles de maximus et minimus a quelques problems de statique relatifs a l'architecture, Acad. R. Sci. Mem. Math. Phys. Divers Savans, 7, 343-382, 1773.

Crowell, J. C., Problems concerning the San Andreas fault system in southern California, in Proceedings of the Conference on Tectonic Problems of the San Andreas Fault System, edited by R. L. Kovach and A. Nur, pp. 125-135, Stanford University Press, Palo Alto, Calif., 1973.

Haimson, B. C., and C. Fairhurst, In situ stress determinations at great depth by means of hydraulic fracturing, in Rock Mechanics-Theory and Practice, Proceedings of 11th Symposium on Rock Mechanics, edited by W. Somerton, pp. 559-684, American Institute of Mining and Engineering, New York, 1970.

Hanks, T. C., Earthquake stress drops, ambient tectonic stresses and stresses that drive plate motions, Pure Appl. Geophys., 115, 441-458, 1977.

Hanks, T. C., Crustal earthquake stress drops, U.S. Geol. Surv. Open File Rep. 80-625, 490-518, 1980.

Hanks, T. C., and C. B. Raleigh, The conference on magnitude of deviatoric stresses in the earth's crust and uppermost mantle, $J$. Geophys. Res., 85, 6083-6085, 1980.

Hickman, S., J. H. Healy, and M. D. Zoback, Recent in situ stress measurements in the Mojave Desert, submitted to Geophys. Res. Lett., 1982.

Hill, D. P., Contemporary block tectonics: California and Nevada, J. Geophys. Res., 87, 5433-5450, 1982.

Jaeger, J. C., and N. G. W. Cook, Fundamentals of Rock Mechanics, Halsted, New York, 1976.

King, N. E., J. C. Savage, and W. H. Prescott, Strain accumulation in Southern California 1973-1981, submitted to J. Geophys. Res., 1982.

Lachenbruch, A. H., and J. H. Sass, Thermomechanical aspects of the San Andreas fault system, in Proceedings of the Conference on Tectonic Problems of the San Andreas Fault System, edited by R. L. Kovach and A. Nur, pp. 192-205, Stanford University Press, Palo Alto, Calif., 1973. 
Lachenbruch, A. H., and J. H. Sass, Heat flow and energetics of the San Andreas fault zone, $J$. Geophys. Res., 85, 6185-6222, 1980.

McGarr, A., Some constraints on levels of shear stress in the crust from observations and theory, J. Geophys. Res., 85, 6231-6238, 1980.

McGarr, A., Analysis of states of stress between provinces of constant stress, submitted to J. Geophys. Res., 1982.

McGarr, A., and N. C. Gay, State of stress in the earth's crust, Annu. Rev. Earth Planet. Sci., 6, 405-436, 1978.

McNally, K. C., H. Kanamori, J. C. Pechmann, and G. Fuis, Earthquake swarm along the San Andreas fault near Palmdale, Southern California, 1976 to 1977, Science, 201, 814-817, 1978.

McTigue, D. F., and C. C. Mei, Gravity-induced stresses near topography of small slope, J. Geophys. Res., 86, 9268-9278, 1981.

Morrow, C. A., L. Q. Shi, and J. D. Byerlee, Strain hardening and strength of clay-rich fault gouges, J. Geophys. Res., 87, in press, 1982.

Prescott, W. H., and A. Nur, The accommodation of relative motion at depth on the San Andreas fault system in California, $J$. Geophys. Res., 86, 999-1004, 1981.

Savage, J. C., Comment on 'An analysis of strain accumulation on a strike slip fault' by D. L. Turcotte and D. A. Spence, J. Geophys. Res., 80, 4111-4114, 1975.

Savage, J. C., and R. O. Burford, Geodetic determination of relative plate motion in central California, J. Geophys. Res., 78, 832-845, 1973.

Savage, J. C., W. H. Prescott, M. Lisowski, and N. E. King, Strain accumulation in southern California, 1973-1980, J. Geophys. Res., 86, 6991-7001, 1981.
Sibson, R. H., Generation of pseudotachylyte by ancient seismic faulting, Geophys. J., 43, 775-794, 1975.

Sibson, R. H., Fault zone models, heat flow and the depth distribution of earthquakes in the continental crust of the United States, Bull. Seismol. Soc. Am., 72, 151-163, 1982.

Sieh, K. E., Prehistoric large earthquakes produced by slip on the San Andreas fault at Pallett Creek, California, J. Geophys. Res., 83, 3907-3939, 1978.

Thatcher, W., Horizontal crustal deformation from historic geodetic measurements in southern California, J. Geophys. Res., 84, 23512370, 1979.

Weldon, R. J., and K. E. Sieh, Offset rate and possible timing of recent earthquakes on the San Andreas fault in Cajon Pass, California (abstract), Eos Trans. AGU, 62, 1048, 1981.

Zoback, M. D., and J. C. Roller, Magnitude of shear stress on the San Andreas fault: Implications from a stress measurement profile at shallow depth, Science, 206, 445-447, 1979.

Zoback, M. D., H. Tsukahara, and S. Hickman, Stress measurements at depth in the vicinity of the San Andreas fault: Implications for the magnitude of shear stress at depth, J. Geophys. Res., $85,6157-6173,1980$.

Zoback, M. L., and M. D. Zoback, State of stress in the conterminous United States, J. Geophys. Res., 85, 6113-6156, 1980.

(Received April 5, 1982; revised July 6, 1982; accepted July 9, 1982.) 